\title{
Flexural Strength of Banana Fibre Reinforced Epoxy Composites Produced through Vacuum Infusion and Hand Lay-Up Techniques - A Comparative Study
}

Mohamed Abd Rahman, Abdul Aziz Jasani and Mohd Azizuddin Ibrahim

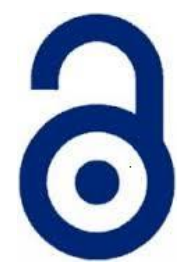

Received: 15 March 2017

Accepted: 30 June 2017

Published: 30 June 2017

Publisher: Deer Hill Publications

(c) 2017 The Author(s)

Creative Commons: CC BY 4.0

\begin{abstract}
Natural fibres from such as kenaf, sisal, pineapple leaf and banana are becoming popular nowadays due to their many advantages over traditional glass fibres in reinforcing polymer composites. These fibres are renewable, abundantly available, economical, lightweight and environmental friendly. This work compared the flexural property of banana fibre-reinforced epoxy composites produced via vacuum infusion and hand layup processes. Banana fibres were treated with sodium hydroxide $(\mathrm{NaOH})$ solution for 1 hour before been dried in the oven for 24 hours at $100^{\circ} \mathrm{C}$. An aluminium vacuum infusion mold was manufactured per the standard flexural test specimen of $127 \mathrm{~mm} x$ $12.7 \mathrm{~mm} \times 3.2 \mathrm{~mm}$. Composite specimens were produced while varying fibre volume fraction of $20 \%$ and $40 \%$ as well as fibre length of $63 \mathrm{~mm}$ and $127 \mathrm{~mm}$. The highest flexural strength of $136.27 \mathrm{MPa}$ was achieved by specimens made by vacuum infusion process with $40 \%$ volume fraction and $63 \mathrm{~mm}$ fibre length while for hand layup process, the highest flexural strength was only $80.71 \mathrm{MPa}$ with equal fibre content and fibre length. At both fibre lengths, using vacuum infusion resulted in the increase in flexural strength in the range of 31.4 to $107.9 \%$ over hand layup. Using vacuum infusion has resulted in banana fibre-reinforced epoxy composites with better flexural properties compared to those produced using hand layup process which allow excellent reinforcing characteristic of banana fibres to be realized.
\end{abstract}

Keywords: Vacuum Infusion, Hand Lay-up, Banana Fibre, Epoxy, Volume Fraction, Fibre Length, Flexural Strength.

\section{INTRODUCTION}

Composites have always attracted interests in the production of goods as this class of materials is known to have excellent properties resulting from the individual components making each composite. The most vital of all the properties are mechanical properties for most applications [1]. Achieving important mechanical properties such as flexural strength cannot be easily done using a single material but is possible with composites [2].

Nowadays, due to environmental and economic reasons, there is an ever-increasing interest in the use of greener materials as replacement of more traditional ones in the production of goods? A good example of this trend is the research done on natural fibres as reinforcing materials in composites. Natural fibres originating from plants such as flax, hemp, jute, kenaf, oil palm, sisal, banana and many more are said to possess many advantages over their synthetic counterparts like glass and carbon fibres. These renewable materials are known to be strong, lightweight, readily available and less hazardous.

Natural fibres are already known to possess numerous advantages with banana fibres becoming more popular with researchers and industrialists [3]. Venkateshwaran and Elayaperumal (2010) reviewed the works done on banana fibres, their uses as composite reinforcing phase and the resulting properties [4]. Banana fibres with their high specific strength can be utilized to produce light weight composites to manufacture light weight automobile interior parts [3]. In a few studies, banana fibres were used to reinforce epoxy while studying effect of fibre length and optimum fibre loading [5 - 7]. In the study of Santhosh et al (2014), 30\% fibre fraction was used without specifying banana fibre length [6]. Raghavendra et al (2012) utilized short banana fibres of length 2 to $10 \mathrm{~mm}$ and a constant 20\% fibre

M. A. Rahman 凶, A. A. Jasani, and M. A. Ibrahim

Department of Manufacturing and Materials Engineering

International Islamic University Malaysia

P.O. Box 10, 50728 Kuala Lumpur, Malaysia

E-mail: mrahman@iium.edu.my

Reference: Rahman, M. A., Jasani, A. A. and Ibrahim, M. A. (2017). Flexural Strength of Banana Fibre Reinforced Epoxy Composites Produced through Vacuum Infusion and Hand Lay-Up Techniques - A Comparative Study. International Journal of Engineering Materials and Manufacture, 2(2), 31-36. 
weight [5]. One study tested the properties of single banana fibres and used them in finite element analysis of banana fibre reinforced composites while assuming continuous banana fibres and $5-20 \%$ fibre weight [8]. Earlier, Laly et al (2003) investigated banana fibre reinforced polyester composites and found that the optimum content of banana fibre is $40 \%$ [9].

To improve wettability, sodium hydroxide is the most commonly used chemical to treat natural fibres $[5,6]$. Alkali treatment or mercerization using sodium hydroxide $(\mathrm{NaOH})$ is the most commonly used treatment for bleaching and cleaning the surface of natural fibres to produce high-quality fibres. Modifying natural fibres with alkali has greatly improved the mechanical properties of the resultant composites.

Most if not all the above studies used hand layup method to produce the composites. Hand layup process is inexpensive and simple but the composites may contain drawbacks like voids, poor fibre compaction and wrinkling [10]. There are other composite processing methods and vacuum infusion composite is one of the well-established methods. In vacuum infusion, resin is drawn into the reinforcing fibres using vacuum resulting in better fibre-to-resin ratio resulting in lightweight and stronger composite products. Vacuum infusion process produced composites with better mechanical properties than hand layup method [11]. Yuhazri et al (2010) however studied polyester composites reinforced with continuous kenaf fibres produced by hand layup and vacuum infusion methods in which they found that tensile strength and modulus of the composites produced using vacuum infusion technique were higher than those produced using hand layup [11].

Despite various works on banana fibres and their uses in reinforcing polymer composites, information on the usage of banana fibres in reinforcing polymers is somewhat limited in the literature [8]. Especially there was little if any on banana fibre reinforced epoxy composites made by using vacuum infusion and comparison of the resultant properties with those produced using hand layup process. Therefore, there was a need to further study the mechanical properties of banana fibre-reinforced epoxy composites using vacuum infusion method. By using this technique to make banana fibre-reinforced epoxy composites, it was expected that higher mechanical properties in particular flexural strength would result which would hopefully lead to higher utilization of these natural fibres for commercial use. To achieve this, banana fibre-reinforced epoxy composite specimens were prepared using vacuum infusion and hand layup methods while experimenting with different fibre contents and fibre lengths and studied the resulting flexural strength.

\section{METHODOLOGY}

Banana fibres were used as reinforcing phase in epoxy composites. The fibres were treated with $5 \% \mathrm{NaOH}$ solution for 2 hours before thoroughly washed under running water. Drying of the fibres was done in the oven for 24 hours at $100^{\circ} \mathrm{C}$. E-110i epoxy resin was used with $\mathrm{H}-10$ hardener in a 2:1 ratio. To make the composite specimens of banana fibre-reinforced epoxy, a vacuum infusion aluminium mold was prepared using CNC milling machine. The mold has cavities with dimensions $127 \mathrm{~mm}$ long, $12.7 \mathrm{~mm}$ wide and $3.2 \mathrm{~mm}$ deep as per ASTM D790 [12]. Figure 1 shows the schematic experimental setup of vacuum infusion (VI) process.

Full factorial experiments were carried out with three factors and two levels (Table 1) totalling 8 experiments. Figure 2 ( $a$ and $b$ ) shows the various banana fibre-reinforced epoxy composites that were successfully manufactured using vacuum infusion $(\mathrm{VI})$ and hand layup ( $\mathrm{HL}$ ) processes. In every specimen, banana fibres were arranged longitudinally in the mold cavities.

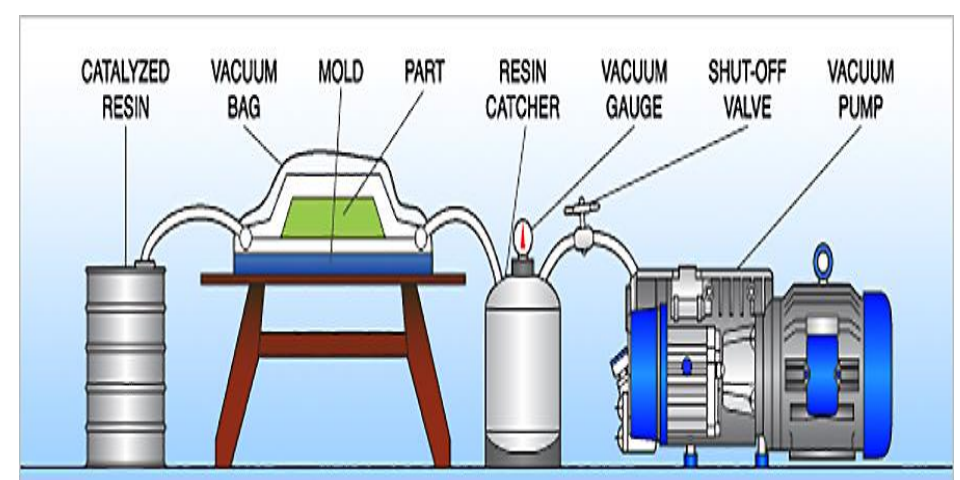

a

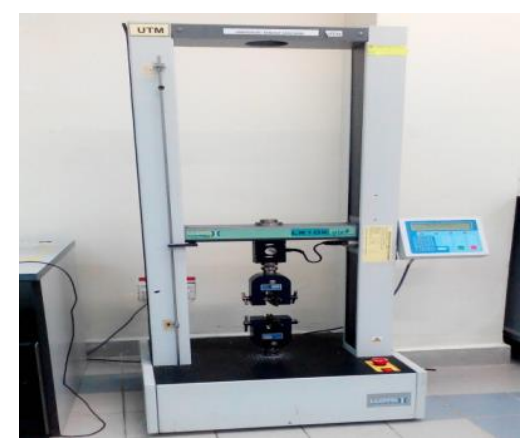

b

Figure 1: Experimental setup; (a) vacuum infusion process, and (b) universal testing machine. 
Table 1: Experimental parameters and responses

\begin{tabular}{cccccccc}
\hline \multirow{3}{*}{ Run } & \multicolumn{3}{c}{ Factors } & \multicolumn{4}{c}{ Flexural Strength (MPa) } \\
\cline { 2 - 6 } & $\begin{array}{c}\text { Volume fraction } \\
(\%)\end{array}$ & $\begin{array}{c}\text { Fiber length } \\
(\mathrm{mm})\end{array}$ & Process & Sample 1 & Sample 2 & Sample 3 & Average \\
\hline 1 & 20 & 127 & $\mathrm{VI}$ & 86.07 & 93.93 & 98.99 & 93.00 \\
2 & 20 & 63 & $\mathrm{VI}$ & 111.98 & 104.24 & 98.29 & 104.84 \\
3 & 40 & 127 & $\mathrm{VI}$ & 133.34 & 144.17 & 121.65 & 133.10 \\
4 & 40 & 63 & $\mathrm{VI}$ & 87.95 & 151.06 & 169.79 & 136.27 \\
5 & 20 & 127 & $\mathrm{HL}$ & 96.71 & 55.02 & 60.68 & 70.80 \\
6 & 20 & 63 & $\mathrm{HL}$ & 64.62 & 60.42 & 66.95 & 63.99 \\
7 & 40 & 127 & $\mathrm{HL}$ & 58.93 & 84.02 & 49.15 & 64.03 \\
8 & 40 & 63 & $\mathrm{HL}$ & 73.23 & 80.45 & 88.46 & 80.71 \\
\hline
\end{tabular}

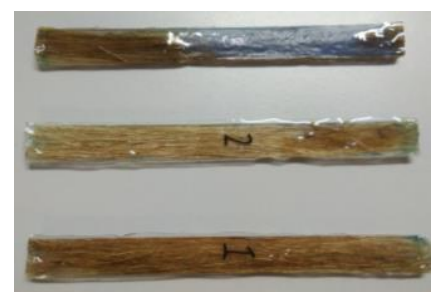

a

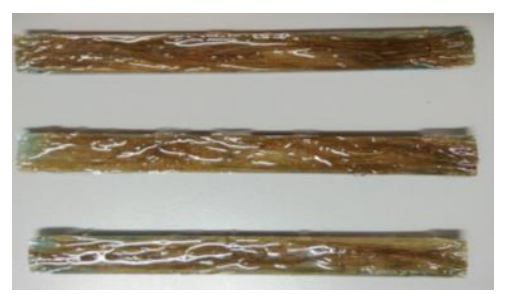

b

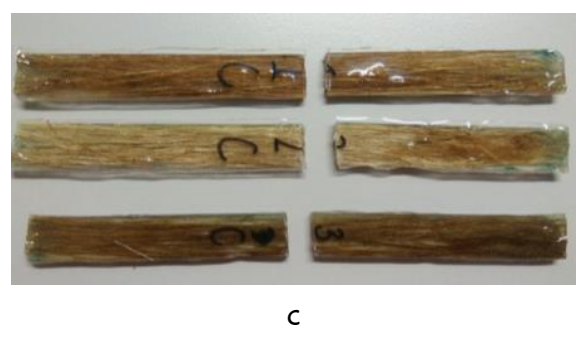

Figure 2: Specimens of banana fiber-epoxy composites; (a) produced by vacuum infusion process, (b) produced by hand layup process, and (c) after undergoing flexural test.

\section{RESULTS AND DISCUSSIONS}

From the analysis of variance of the flexural strength data (see Table 2), fibre content and process type significantly affect the composite flexural strength. Fibre length did not seem to affect flexural strength significantly as both lengths may be considered to represent long fibres. Raghavendra et al (2012) determined that optimal condition was at 4 $\mathrm{mm}$ length for banana fibre-reinforced epoxy composites when studying the effect of fibre length on tensile strength. They reported slight decrease of tensile strength when longer fibre lengths used [5].

Similar flexural strength values were obtained by Santhosh et al (2014) when they studied banana fibre-reinforced epoxy composites produced using hand layup [6]. At $20 \%$ and $40 \%$ fibre content, using vacuum infusion resulted in $63.8 \%$ and $68.8 \%$ increase in flexural strength respectively compared to hand layup. This increase was also consistent with works using conventional fibres in which flexural strength of material prepared by vacuum infusion almost double compared to those prepared using hand layup method [13].

Table 2: Analysis of Variance of Flexural Strength Data

\begin{tabular}{lccccc}
\hline Sources of Variation & SS & DOF & MS & $F_{\circ}$ & P-Value \\
\hline Fibre content (A) & 2486.77 & 1 & 2486.77 & 6.72 & 0.0196 \\
Fibre length (B) & 233.00 & 1 & 233.00 & 0.63 & 0.4390 \\
Process Type (C) & 13198.60 & 1 & 13198.60 & 35.69 & 0.0000 \\
AB & 82.81 & 1 & 82.81 & 0.22 & 0.6425 \\
AC & 1420.19 & 1 & 1420.19 & 3.84 & 0.0677 \\
BC & 10.06 & 1 & 10.06 & 0.03 & 0.8711 \\
ABC & 386.72 & 1 & 386.72 & 1.05 & 0.3217 \\
Error & 5917.63 & 16 & 369.85 & & \\
Total & 23735.78 & 23 & & & \\
\hline
\end{tabular}


Figures 3 and 4 indicate clearly that using vacuum infusion made it possible to realize the reinforcing capability of the banana fibres as the fibre content increased. At both fibre lengths used, increasing fibre content resulted in large increases in composite flexural strength. Similar increases were not obtained using hand layup method. In fact, a slight reduction in flexural strength was observed. This is somewhat expected as hand layup process signifies variation in composite properties due to sources such skill, inability to remove air bubbles trapped, difficulty in handling large amount of fibre content. On the other hand, use of vacuum infusion entails more consistent process.

Figures 5 and 6 below further indicate the benefits of using vacuum infusion method over hand layup method. It is clear that increasing the fibre content resulted in the increase in flexural strength. However, at each fibre content in the vacuum infusion process, using longer fibres resulted in very slight decreases in flexural strength. Similar decrease in flexural strength was also observed another previous work [8]. Since the length of banana fibres extracted from the tree trunks is inconsistent, shorter fibre lengths may be utilized in composite processes without jeopardizing the properties significantly.

Figure 7 above shows the flexural strength of the specimens with $40 \%$ fibre content and specimens of neat resin made by vacuum infusion process. At $40 \%$ fibre content, the use of vacuum infusion resulted in $29.7 \%$ increase in flexural strength compared to neat resin. Additionally, the specimens with $40 \%$ volume fraction achieved highest flexural strength at 136.27MPa. The variations of flexural strength for the samples prepared by vacuum infusion process and hand layup process are compared as shown in Figure 8.

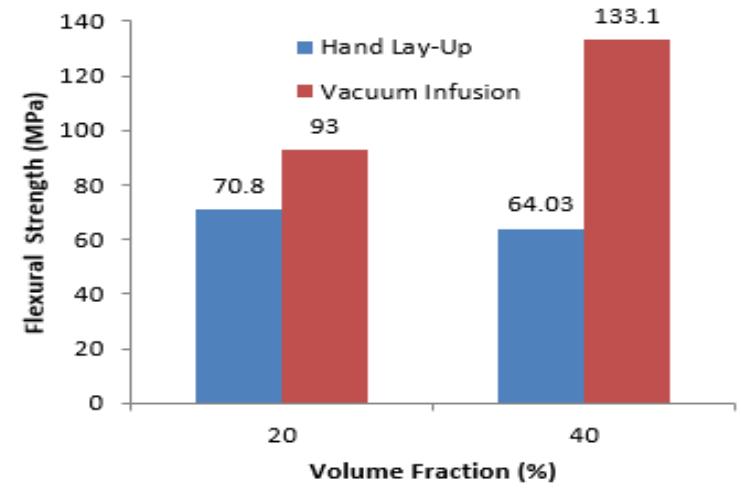

Figure 3: Shows the relationship of volume fraction on flexural strength of specimens with fiber length 127 $\mathrm{mm}$

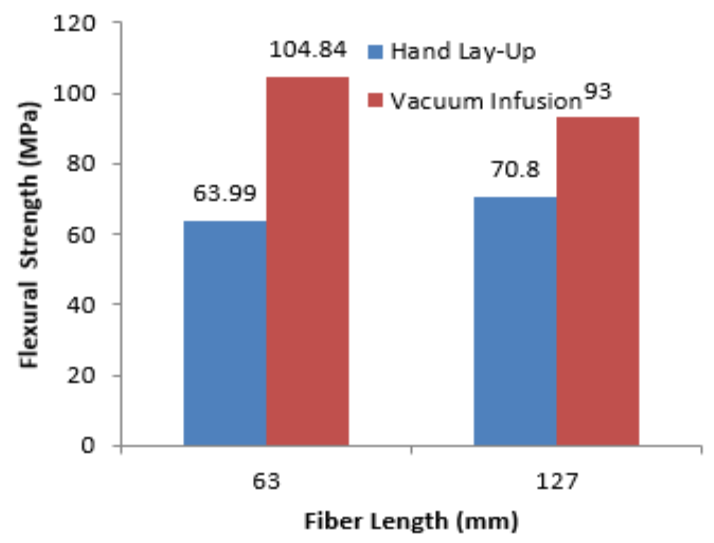

Figure 5: Shows the relationship of volume fraction on flexural strength of specimens with volume fraction $20 \%$

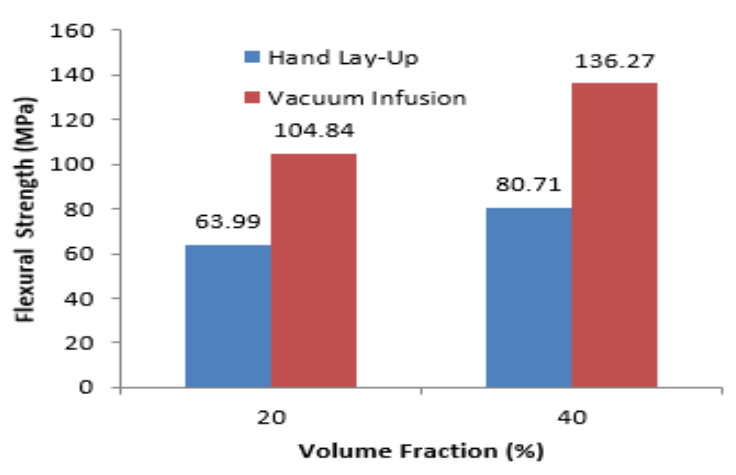

Figure 4: Shows the relationship of volume fraction on flexural strength of specimens with fiber length $63 \mathrm{~mm}$

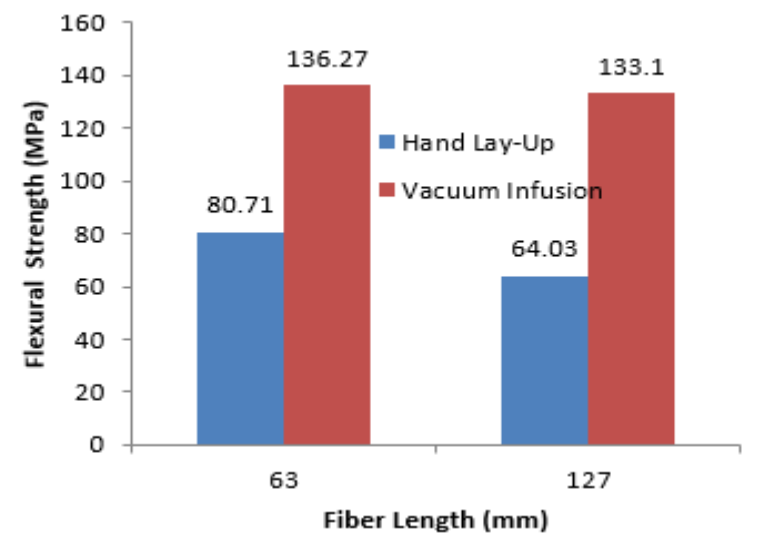

Figure 6: Shows the relationship of fiber length on flexural strength of specimen with volume fraction $40 \%$. 


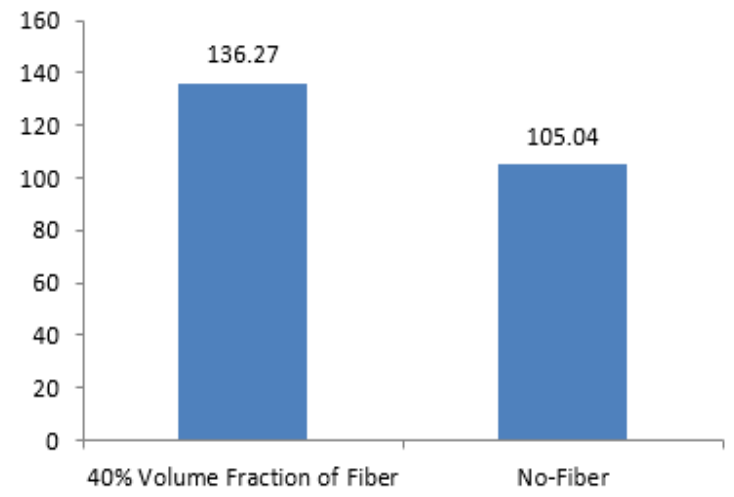

Figure 7: Relationship between specimen with $40 \%$ volume fraction offiber and specimen with no-fiber manufacture by vacuum infusion process.

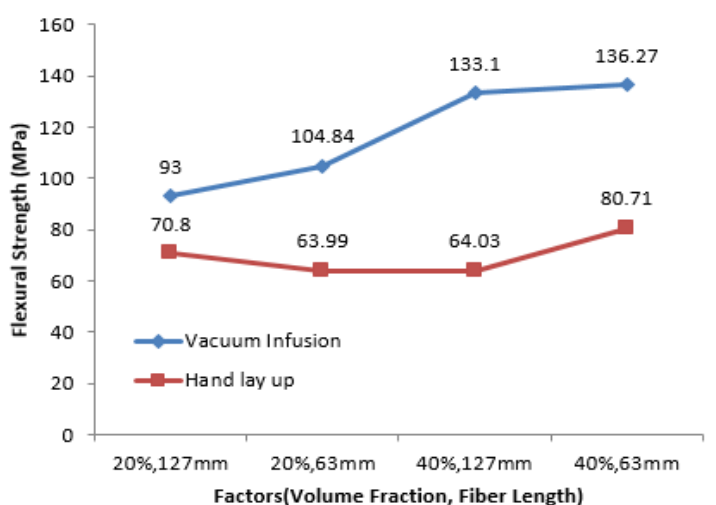

Figure 8: The Variation of flexural strength of specimens with different factors produce with different process.

The above results clearly indicate the advantages of vacuum infusion process in terms of producing banana fibre reinforced composites with better mechanical properties hence quality. The vacuum causes bubbles from resin to be removed from the experimental setup and atmospheric pressure to compress the fibre laminates forcing better wetting of the fibres by the resin. Better wetting of fibres led to better fibre-matrix interface and the resultant higher flexural strength. In contrast, for hand lay-up method, the process was carried out in environment exposed to moisture and other gases which could react thus affect the composites during curing process [11].

Vacuum infusion may be used to produce greener products made of polymer composites reinforced with natural fibres like banana fibres. Excellent characteristics of natural fibres as reinforcing phase in composites may be realized. Not only product quality will be increased, an eco-friendlier and less wasteful process will result.

\section{CONCLUSIONS}

In this study, banana fibre-reinforced epoxy composites were successfully made using hand layup and vacuum infusion methods. Flexural properties of these composites were studied with $20 \%$ and $40 \%$ fibre contents and $63 \mathrm{~mm}$ and $127 \mathrm{~mm}$ fibre lengths. It may be concluded that:

1. Using vacuum infusion method to produce banana fibre-reinforced epoxy composites resulted in an increase in flexural strength compared to neat resin with a maximum of $29.7 \%$ increase at $40 \%$ fibre content.

2. Banana fibre-reinforced composites had higher flexural strength when produced using vacuum infusion process.

3. At both $63 \mathrm{~mm}$ and $127 \mathrm{~mm}$ fibre length, increasing fibre content from $20 \%$ to $40 \%$ resulted in the increase in flexural strength by $30.0 \%$ and $43.1 \%$ respectively. In similar instances, the use of hand layup resulted in reductions in flexural strength.

4. At both fibre lengths, using vacuum infusion resulted in the increase in flexural strength in the range of 31.4 to $107.9 \%$ over hand layup.

5. At both 20 and $40 \%$ fibre contents, flexural strengths slightly reduced upon using $127 \mathrm{~mm}$ over $63 \mathrm{~mm}$ long fibres. Using hand layup resulted modest increase and even higher reduction respectively.

6. At both fibre contents, using vacuum infusion however resulted in much greater increases in flexural strength compared to the use of hand layup.

7. The highest flexural strength was obtained with a specimen having $40 \%$ fibre content and $63 \mathrm{~mm}$ fibre length produced by vacuum infusion process which is $136.27 \mathrm{MPa}$.

8. Vacuum infusion has been shown to produce banana fibre-reinforced epoxy composites with better flexural properties compared to those produced using hand layup process. Combination of other natural fibres can be used with banana fibres to develop hybrid composites and the properties determined. Filler material can be also used in the composites for possible improvements of the composite properties.

\section{ACKNOWLEDGEMENT}

The authors are grateful to the International Islamic University Malaysia for funding the study and the Kulliyyah of Engineering where the experimental studies were conducted. 


\section{REFERENCES}

1. Nielsen, L.E. \& Landel, R.F. (1994). Mechanical properties of polymers and composites. $2^{\text {nd }}$, New York: Marcel Dekker Inc.

2. Begum, K. \& Islam, M. A. (2013). Natural fiber as a substitute to synthetic fiber in polymer composite: a review. Research Journal of Engineering Sciences, 2(3), 46-53.

3. Ashwin Sailesh and S.Prakash, S. (2013). Review on Recent Developments in Natural Fiber Composites. International Journal of Engineering Research \& Technology (IJERT), 2(9), 2523-2525.

4. Venkateshwaran, N. and Elayaperumal, A. (2010). Banana Fiber Reinforced Polymer Composites - A review. Journal of Reinforced Plastics and Composites, 29(15), 2387-2396.

5. Raghavendra. S, P.Balachandrashetty, P., Mukunda, P. G. and Sathyanarayan, K. G. (2012). The Effect of Fiber Length on Tensile Properties of Epoxy Resin Composites Reinforced by the Fibres of Banana. International Journal of Engineering Research \& Technology (IJERT), 1(6), 1-3.

6. Santhosh, J., Balanarasimman, N., Chandrasekar, R. and Raja, S. (2014). Study of Properties of Banana Fiber Reinforced Composites. International Journal of Research in Engineering and Technology (IJRET), 3(11), 144-150.

7. Vinod, B. and Sudev, L. J. (2013). Effect of Fiber length on the Tensile Properties of PALF Reinforced Bisphenol Composites. International Journal of Engineering, Business and Enterprise Applications (IJEBEA), 13(262), 158162.

8. Shashi Shankar, P., Thirupathi Reddy, K. and Chandra Sekhar, V. (2013). Mechanical Performance and Analysis of Banana Fiber Reinforced Epoxy Composites. International Journal of Recent Trends in Mechanical Engineering (IJRTME), 1(4), 1-10.

9. Laly A. Pothana, Zachariah Oommenb, and Thomas S, "Dynamic Mechanical Analysis of Banana Fiber Reinforced Polyester Composites”, Composites Science and Technology, 63(2), 2003, pp. 283-29.

10. Delaney, J. C., \& Karbhari, V. (2006). The assessment of aspects related to defect criticality in CFRP strengthened concrete flexural members. Rep. No. SSRP 06/11, Dept. of Structural Engineering, Univ. of California-San Diego, La Jolla, CA.

11. Mohammad Yuhazri, Y., Phongsakorn, P. T., \& Haeryip Sihombing. (2010). A comparison process between vacuum infusion and hand lay-up method toward kenaf-polyester composites. International Journal of Basic \& Applied Sciences IJBAS-IJENS. 10(3), 54-57.

12. American Standard of Testing and Materials-ASTM International (2003). Standard Test Methods for Flexural Properties of Unreinforced and Reinforced Plastic and Electrical Insulating Materials. United State, ASTM D79003.

13. Bhatnagar, A. and Niranjan Kumar, I. N. (2015). Vacuum Infusion Process for Composite Vessel Construction. International Journal of Innovative Research \& Development. 4(7), 1-7. 